\title{
Ultrastructure of bovine preantral follicles: effect of the slaughterhouse aseptic process on follicular integrity
}

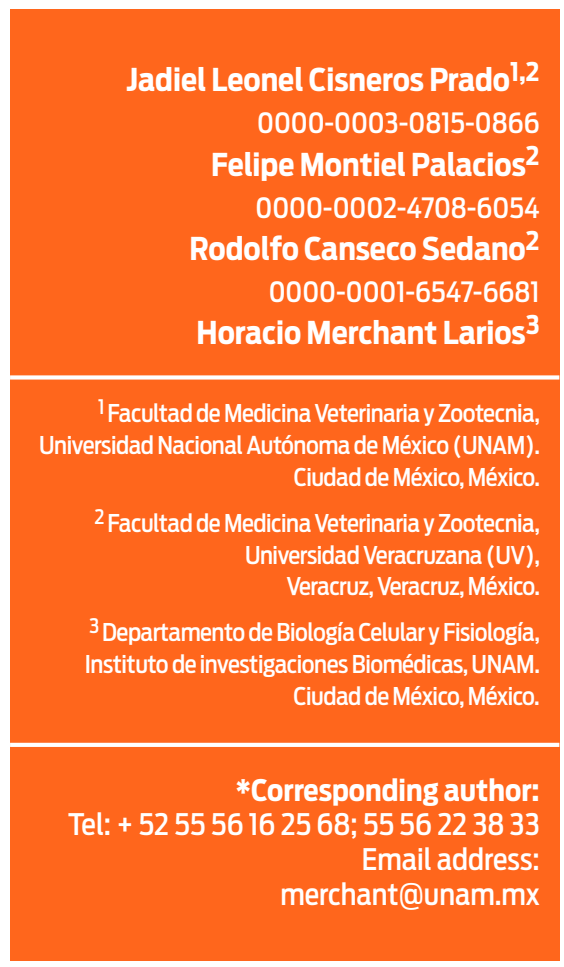

Received: 2016-11-04 Accepted: 2017-04-18

Published: 2017-05-05

Additional information and declarations can be found on page 10

@C Copyright 2017
Jadiel Leonel Cisneros Prado open access $\boldsymbol{2}$

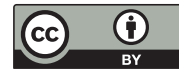

Distributed under Creative Commons CC-BY 4.0

\begin{abstract}
Ovaries from slaughtered cows are the most abundant source of preantral immature follicles for in vitro studies including maturation and in vitro fertilization. Integrity of immature follicles may be compromised by inadequate management during the collection and transport of the gonads, limiting the success of a correct evaluation. This study assessed the effect of aseptic and transport of bovine ovaries on the structural and ultrastructural integrity of immature follicles from the ovarian cortex. Ovaries from 20 different crossbred cows (Bos taurus $\times B$. indicus) were randomly assigned to one of two aseptic and transport treatments: (1) the ovaries were washed once with $70 \%$ ethanol for $10 \mathrm{~s}$, rinsed twice with normal saline solution (OH + NSS), and then transported in NSS $+0.05 \%$ gentamicin sulphate; or (2) the ovaries were washed three times with phosphate buffered saline (PBS) and transported in PBS $+0.05 \%$ gentamicin sulphate. Samples of the ovarian cortex were obtained from each treatment group. Half of samples of each treatment was processed for histologic evaluation of follicular morphology and developmental stage using haematoxylin \& eosin, and the other half was processed to analyse the ultrastructure of immature follicles using transmission electronic microscopy. The rates of good-quality follicles were $36.95 \%$ and $88.6 \%$ for $\mathrm{OH}+$ NSS and PBS, respectively. Histological analysis showed higher number of abnormal follicles in $\mathrm{OH}+\mathrm{NSS}$ than in PBS treated ovaries $\left(F_{1,12}=\right.$ 99.64, $P=0.0001)$. The proportions of morphological alterations were not significantly different between treatments $\left(\chi^{2}{ }_{1,7}=7.72, P=0.358\right)$. The ultrastructure of immature follicles from $\mathrm{OH}+$ NSS ovaries showed cell damage, revealed by abundant cell detritus around both, the oocyte and follicular cells. However, the presence of alterations was barely evident in both the cytoplasm and the nucleus of the granulosa cells.
\end{abstract}

Keywords: aseptic process, ovarian tissue, immature follicles, cattle.

\section{Cite this as:}

Cisneros Prado JL, Montiel Palacios F, Canseco Sedano R, Merchant Larios H. Ultrastructure of bovine preantral follicles: effect of the slaughterhouse aseptic process on follicular integrity. Veterinaria México OA. 2017;4(2). doi: 10.21753/vmoa.4.2.424. 


\section{Introduction}

The preantral ovarian follicle is a defined developmental unit consisting of a single oocyte surrounded by layers of somatic granulosa cells enveloped by a basal membrane. During postnatal life, most oocytes are as quiescent primordial follicles within a single layer of a few "flat" squamous, nonproliferating granulosa cells. ${ }^{1}$ Upon growth activation, the granulosa cells switch to a cuboidal morphology and begin to proliferate while the oocyte initiates the growth phase (primary follicles). Follicle development consists of continued proliferation and differentiation of the granulosa layers, acquisition of an additional cell layer outside the basement membrane (termed the theca), and continued oocyte growth (secondary or preantral follicle). ${ }^{2}$ In the past decade, great emphasis has been placed on the population of preantral immature follicles present in the ovarian cortex, which constitutes an abundant reserve and represents an alternative for the development of cell cultures, ${ }^{3}$ in situ transplants ${ }^{4}$ and cryopreservation,, 6 in addition to preserving steroidogenic functions of the ovarian cortex. ${ }^{7}$ During ovary collection from cows at the slaughterhouse, the possible effect of the aseptic process on the delicate integrity of preantral immature follicles found at the edge of the ovarian cortex is not usually considered. Various studies assumed that the drastic reduction in the number of bacteria in the ovaries achieved with $70 \%$ ethanol during ovary collection is sufficient to obtain ideal ovarian tissue samples for culture or cryopreservation. $8,9,10$ However, ethanol has the ability to trigger oxidative stress at the cytoplasmic membrane in liver and kidney tissue. ${ }^{11}$ Such stress results from the inability of the antioxidant defenses to combine with the oxygen reactive species through the electron transport chain in the mitochondria, and though this alcohol toxicity-mediated mechanism is complex, it promotes the transition of the mitochondrial permeability, leading to apoptosis. ${ }^{11,12,13}$

Replication of the aseptic and transport procedures for ovaries used by several researchers ${ }^{8,9,14-17}$ showed great variations in the integrity of preantral immature follicles, including non-treated follicles. It remains unclear whether the observed variations could be associated with the aseptic process of ovarian collection and transport to the laboratory. Therefore, the aim of this study was to evaluate the effect of the aseptic process after the collection and transport of bovine ovaries on the structural and ultrastructural integrity of preantral immature follicles from the ovarian cortex.

\section{Material and methods} Samples preparation

Ovaries $(n=20)$ from crossbred female cattle (Bos taurus $\times$ B. indicus; 3-5 years old) were collected immediately after slaughter at a local abattoir. Ovaries were assigned to one of the following treatments: $(1)$ the ovaries $(n=10)$ were washed once with $70 \%$ ethanol for $10 \mathrm{~s}$ (J.T. Baker $\left.{ }^{\circledR}, \mathrm{MEX}\right)$, rinsed twice with normal saline solution $\left(\mathrm{OH}+\mathrm{NSS} ; \mathrm{PISA}{ }^{\circ}, \mathrm{MEX}\right)$, and then placed in a transport medium based on NSS $+0.05 \%$ gentamicin sulphate (Gentalex®Fuerte, PISA, MEX); or (2) the ovaries $(n=10)$ were washed three times with phosphate buffered saline (PBS; Bioniche ${ }^{\circledR}$, USA), and transported in a medium containing PBS $+0.05 \%$ gentamicin sulphate.

The ovaries were transported to the laboratory in sealed containers at $4{ }^{\circ} \mathrm{C}$ within 1-3 $\mathrm{h}$ after collection. At the laboratory, each ovary was immediately placed in 
a sterile Petri dish (Falcon ${ }^{\circledR} 100 \times 15 \mathrm{~mm}$ ) containing modified human tubal fluid medium (HTF HEPES ${ }^{\circledR}$; In Vitro Care ${ }^{\circledR}$; USA), supplemented with foetal bovine serum (FBS; BioWest ${ }^{\circledR} ;$ USA). With the aid of dissection tweezers and a scalpel blade (Num. 12), each ovary was divided to obtain six small cortex samples ( $2 \mathrm{~mm} \times$ $1 \mathrm{~mm} \times 1 \mathrm{~cm}$ ). Three samples of cortex from each ovary were fixed in buffered formalin, embedded in paraffin squares, cut at $7 \mu \mathrm{m}$ and stained with hematoxylin \& eosin (H\&E) to evaluate the follicular morphology and development stage under a light microscope (B150DB-R, Optika ${ }^{\circledR}$, Italia). The follicles were classified as primordial (a single layer of flat cells surrounding the oocyte), primary (a single layer of cuboidal granulosa cells), or secondary (two or more layers of cuboidal granulosa cells surrounding the oocyte). ${ }^{18}$ Based on their morphology, the follicles were also classified as normal or atretic, according to the presence or absence of pyknotic nucleus, oocyte retraction, and/or disorganization of the granulosa cells and separation from the basal membrane. ${ }^{19}$

The remaining three samples of ovarian cortex from each ovary were used to conduct a more detailed evaluation through an ultrastructural analysis of the immature follicles. The tissue fragments were fixed in Karnovsky solution (2\% paraformaldehyde and $2.5 \%$ glutaraldehyde in $0.1 \mathrm{M}$ sodium cacodylate buffer $\mathrm{pH}$ 7.2) for $24 \mathrm{~h}$ at $4{ }^{\circ} \mathrm{C}$. After fixation, the tissue fragments were washed in $0.1 \mathrm{M}$ sodium cacodylate buffer and mechanically isolated with a scalpel due to the non-homogeneous degree of follicular density and distribution in the ovarian tissue, which affects interpretation. ${ }^{20,21}$ Then, the tissue fragments were post-fixated in $1 \%$ osmium tetroxide in Zetterqvist buffer for $1 \mathrm{~h}$. Subsequently, the samples were dehydrated in gradually doses of ethanol (50,70, 80, 90 and $100 \%)$ for 15 min each one, moved to acetonitrile for $20 \mathrm{~min}$, and then embedded in proportions 1:1, 2:1 of EPON 812 resin:acetonitrile, for $1 \mathrm{~h}$ each, and finally in only EPON 812 resin for $24 \mathrm{~h}$. The semi-fine cuts $(1-2 \mu \mathrm{m})$ were stained with toluidine blue. The fine cuts (60-70 nm) were contrasted with uranyl acetate and lead citrate and examined by transmission electron microscopy (Jeol JEM 100C). ${ }^{22}$

\section{Statistical analysis}

The follicles in different development stages with normal morphology in each treatment group were counted and expressed as a percentage \pm one standard deviation (SD). Data were analysed by ANOVA and the Tukey's test to determine the differences between treatments. The main morphological abnormalities observed (categorical variables) by light microscopy are presented as a percentage, and the data were analysed using $\chi^{2}$ to determine the homogeneity of proportions. For all the tests, Statistica v. 10.0 software was used and values of $P<0.05$ were considered statistically significant.

\section{Results and discussion}

\section{Histological analysis}

In total, 626 immature follicles were evaluated. The overall percentages of follicles in the primordial, primary and secondary development stages were $71.4 \%, 21.0 \%$, 
and $7.6 \%$, respectively. The percentage of high quality follicles (classified as normal follicles) obtained from the PBS and OH + NSS treated groups, was $88.6 \%$ and $36.9 \%$, respectively. The histological results between the PBS and OH + NSS treatments showed differences in the number of normal follicles in the evaluated samples of ovarian cortex (Figure 1), with a higher number and quality in those treated with $\mathrm{PBS}\left(F_{1,12}=99.64, P=0.0001\right)$. Statistical analysis also showed differences between development stages within each of the treatments groups $\left(F_{2,12}=262.67\right.$, $P=0.0001$; Table 1). Light microscopy was used to evaluate atretic abnormalities in the ovarian tissue samples from each treatment group, and the proportion of alterations to immature follicles was not different between the two treatments $\left(\chi^{2} 1,7=7.72, P=0.358\right.$; Table 2$)$.

\section{Ultrastructural analysis}

The semi-fine cuts stained with toluidine blue revealed diverse structural alterations among the follicles of each treatment group (10 follicles for treatment; Figure 2). Ultrastructural evaluation confirmed that the oocytes from immature follicles present in the samples of the ovarian cortex treated with $\mathrm{OH}+$ NSS were completely damaged, as only detritus and a high number of vesicles in the space that corresponds to the immature follicle was observed (Figures 3A-3E). However, at least 64 $\%$ of granulosa cells within the ten analysed follicles retained their integrity (Figures 3E-3F). This result suggests that granulosa cells may have unique characteristics rendering them more resistant to the effects of dehydration and oxidative stress induced by the alcohol applied during the asepsis process.

A large amount of lipid droplets surrounded by polysaccharides was present in all the observed granulosa cells (Figures 3D-3F). Likewise, abundant mitochondria with well delimited cristae were evenly distributed throughout the cytoplasm of the granulosa cells (Figures 3D-3F). Other abundant cytoplasmic organelles were the rough and smooth endoplasmic reticulum and the ribosomes. The nuclei of the granulosa cells were pleomorphic and showed abundant heterochromatin and euchromatin, and this level of evaluation did not reveal significant damage. Consequently, the tight union of the granulosa cells membranes was also observed (Figure 3F).

On the other hand, the evaluation of the immature follicles present in the cortex of ovaries treated with PBS confirmed that those follicles were not affected compared with those treated with $\mathrm{OH}+\mathrm{NSS}$. The ultrastructure of the immature follicles revealed basal membranes formed by a basal lamina and collagen fibers which provide support and firmness to the follicle within the ovary (Figures $4 \mathrm{~A}$ and $4 \mathrm{~B})$. The nuclei of the granulosa cells of the primary and secondary follicles were mostly pleomorphic and had abundant heterochromatin. The cytoplasmic organelles, such as the mitochondria, Golgi apparatus, smooth and rough endoplasmic reticulum, and lysosomes were distributed throughout the cytoplasm and had a normal appearance. Occasional small vesicles with lipids inside were also found in the cytoplasm (Figure 4A).

In the oocytes from primary and secondary follicles, the Golgi apparatus was well developed and occupied a large part of the cytoplasm. The amount of smooth and rough endoplasmic reticulum was diminished and the presence of lipid droplets was scarce compared to the granulosa cells. The size, shape and ultrastructure 


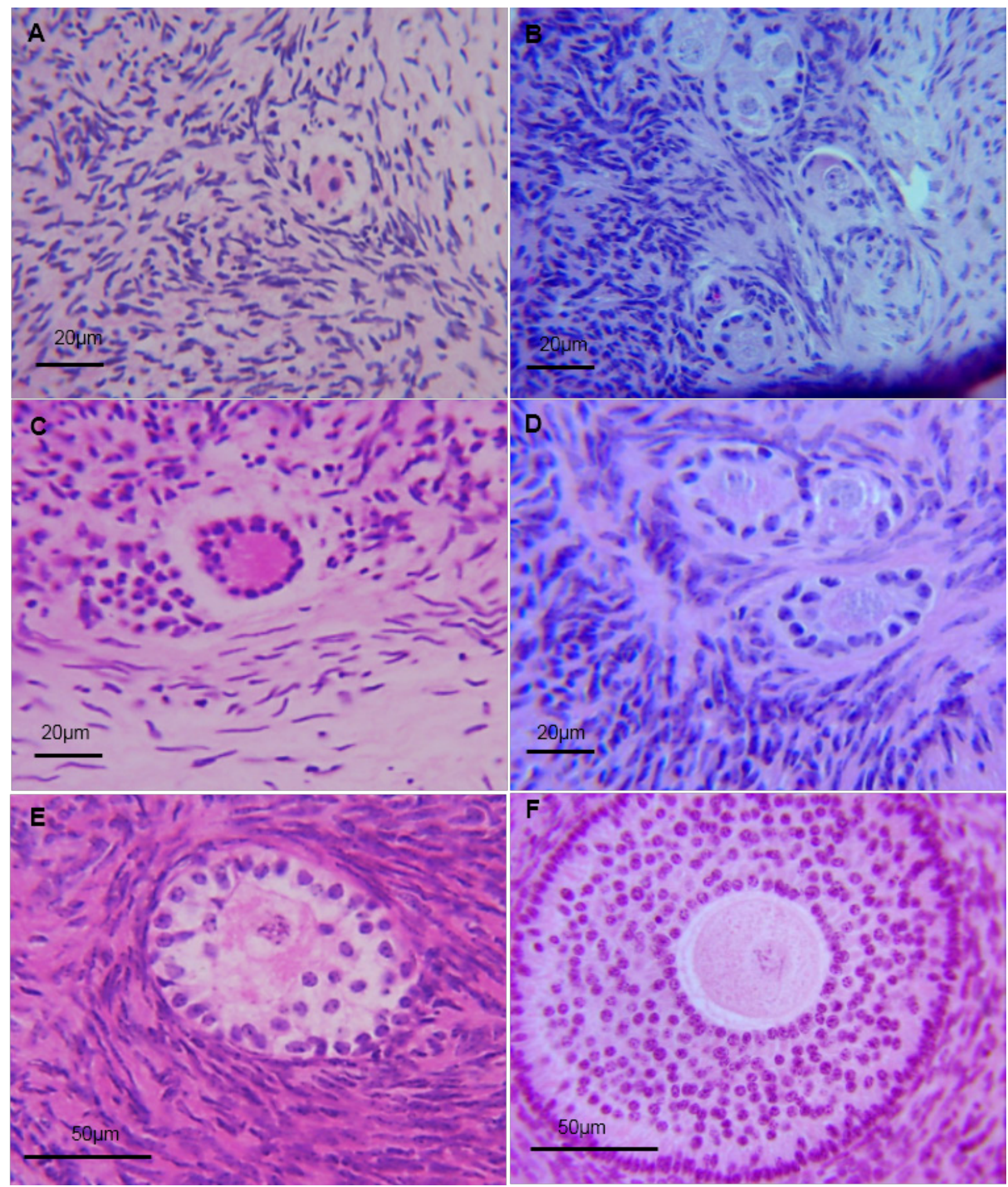

Figure 1. Images A, C, and E were observed in the samples of ovarian tissue corresponding to $\mathrm{OH}+\mathrm{NSS}$ treatment; images $B, D$, and $F$ correspond to PBS treatment. Good-quality primordial ( $A$ and $B$, viewed at $40 X)$, primary $(C$ and $D$, viewed at $40 X$ ), and secondary ( $E$ and $F$, viewed at 10X) immature follicles presents in the samples of bovine ovarian cortex. 
Table 1. The percentage of normal bovine follicles at each stage of development obtained from ovaries retrieved from a slaughterhouse, using two aseptic methods during collection and transport to the laboratory.

\begin{tabular}{|c|}
\hline Groups \\
\hline Primordial \\
\hline Primary \\
\hline Secondary \\
\hline
\end{tabular}

\begin{tabular}{|c|c|}
\hline \multicolumn{2}{|c|}{ Treatments during collection and transport of ovaries } \\
\hline OH+NSS & PBS* \\
\hline $43.6 \pm 5.6^{\mathrm{a}}(102 / 234)$ & $90.6 \pm 4.5^{\mathrm{d}}(193 / 213)$ \\
\hline $12.7 \pm 1.2^{\mathrm{b}}(8 / 63)$ & $87.0 \pm 4.6^{\mathrm{e}}(60 / 69)$ \\
\hline $36.4 \pm 2.1^{\mathrm{c}}(8 / 22)$ & $76.0 \pm 1.2^{f}(19 / 25)$ \\
\hline
\end{tabular}

Data are expressed as percentage $\pm 1 \mathrm{SD}$. The values in parenthesis are the observed number of follicles with good morphology divided by the total number analysed for each group during histological evaluation.

*Statistically different from those treated with $\mathrm{OH}+\mathrm{NSS}\left(F_{1,12}=99.64, P=0.0001\right)$.

$a, b, c, d, e, f$ Different superscripts indicate significant difference in each stage of follicular development $\left(F_{2,12}=262.67\right.$, $P=0.0001)$.

Table 2. Main morphological alterations found in atretic immature follicles in samples of ovarian cortex treated with $\mathrm{OH}+\mathrm{NSS}$ or PBS during collection.

\begin{tabular}{|c|c|c|}
\hline \multirow{2}{*}{ Morphological alterations } & \multicolumn{2}{|c|}{$\begin{array}{c}\text { Treatment during collection and transport of the ovary } \\
\text { \% (number of observations/total) }\end{array}$} \\
\cline { 2 - 3 } & $\begin{array}{c}\text { OH + NSS } \\
\text { Partial crenation }\end{array}$ & $13.9(28 / 201)$ \\
\hline Complete crenation & $10.4(21 / 201)$ & $14.3(5 / 35)$ \\
\hline Cytoplasmic vacuolation of the oocyte & $8.9(18 / 201)$ & $8.6(3 / 35)$ \\
\hline Vacuolation of the follicle & $5.5(11 / 201)$ & $2.8(1 / 35)$ \\
\hline Disorganization of granulosa cells & $29.4(59 / 201)$ & 0 \\
\hline Partial or complete detachment of & $25.9(52 / 201)$ & $48.6(17 / 35)$ \\
\hline granulosa cells and oocyte & $4(8 / 201)$ & $22.9(8 / 35)$ \\
\hline Nuclear pyknosis & $2(4 / 201)$ & $2.8(1 / 35)$ \\
\hline Multinucleation & & 0 \\
\hline
\end{tabular}

Data are expressed as percentage of the total of each column for the main alterations found among follicles for each treatment. The proportions of morphological alterations between treatments did not show significant difference $\left(\chi^{2}{ }_{1,7}=7.72, P=0.3581\right)$. 

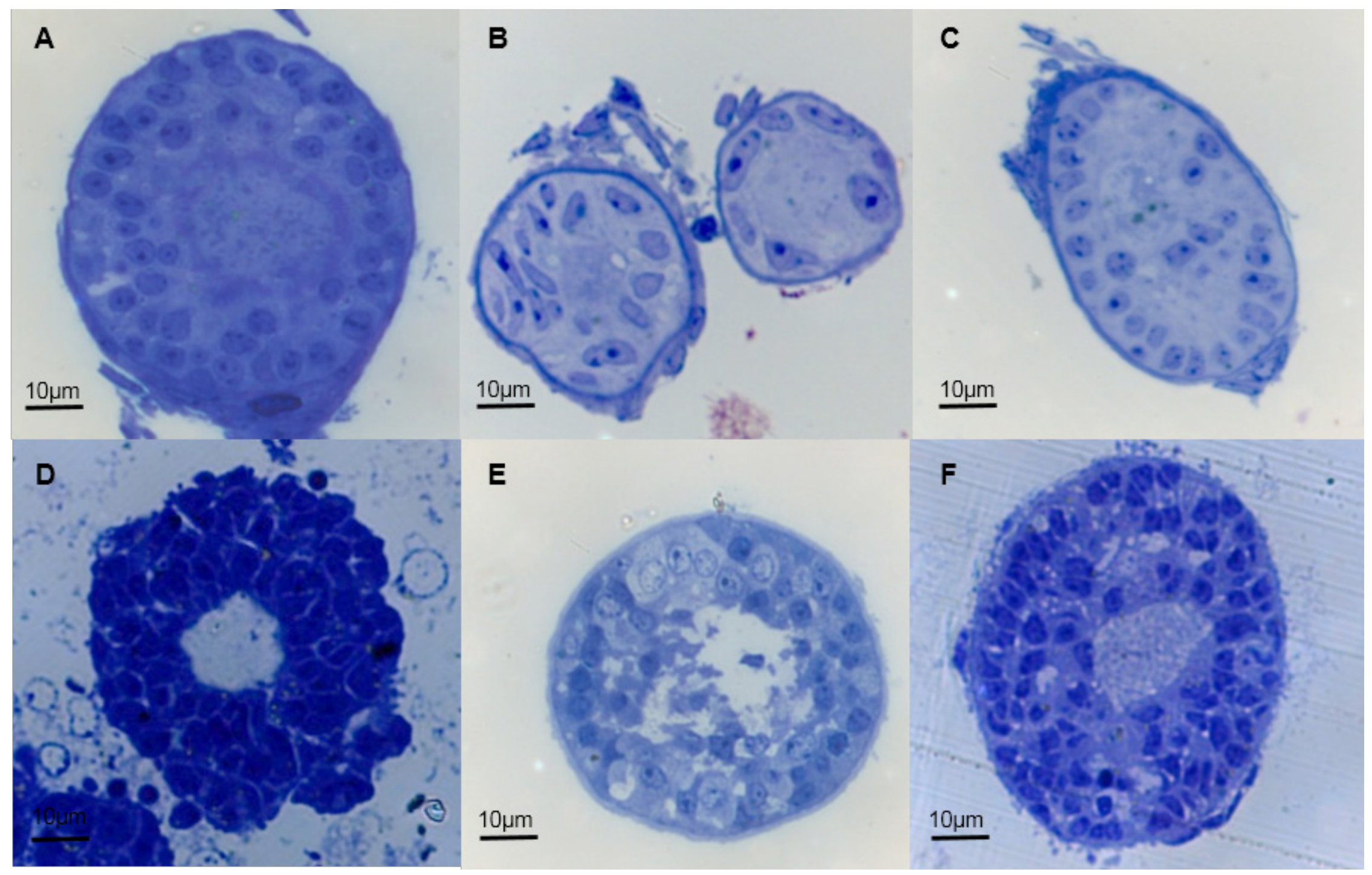

Figure 2. Semi-fine cuts of immature follicles present in bovine ovarian cortex treated with PBS (A, B, C; viewed at 40X) or OH+NSS (D, E, F; viewed at 40X). 


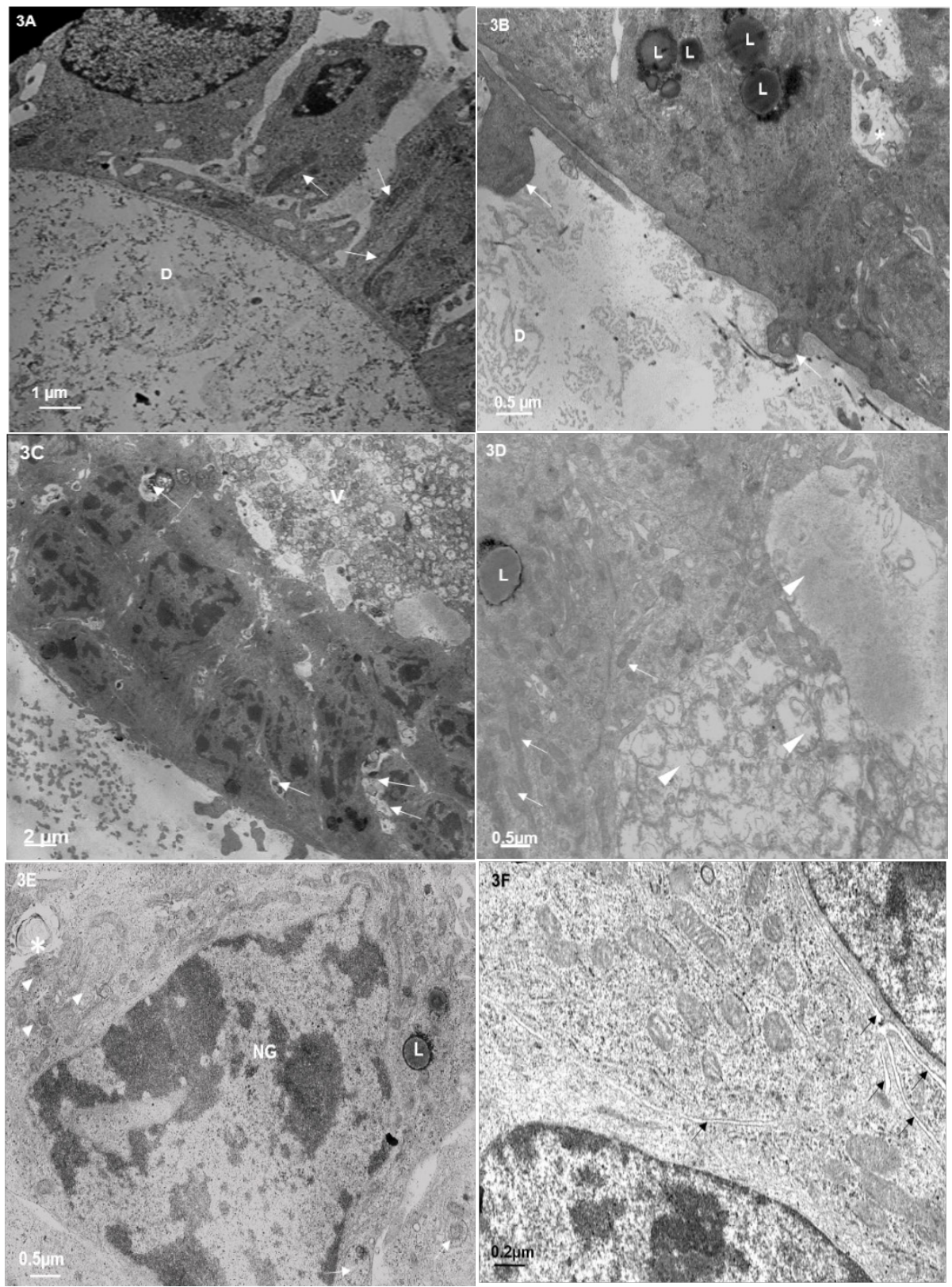

Figure 3. Ultrastructure of bovine immature follicles present in the ovarian cortex treated with $\mathrm{OH}+\mathrm{NSS}$ immediately after ovary collection at the slaughterhouse. The ovaries were rinsed with $70 \%$ ethanol $(\mathrm{OH})$ and then transported to the laboratory in normal saline solution (NSS) according to an established protocol. A) Degenerated primary immature follicle. Detritus is present (D) in the space corresponding to the oocyte. The granulosa cells are separated and cytoplasmic residue is evident in each cell. Inside the cytoplasm, mitochondrial remains are present (arrows). B) The empty space with cell detritus (D) left by the disintegrated oocyte is shown. The electron dense cytoplasm of the granulosa cells has some irregular extensions towards the hollow space (thin arrows). Some mitochondrial remnants are evident in autophagic areas (asterisks). A lipid droplets can be observed (L) C) A secondary follicle with a large number of vesicles (V). The remaining organelles are part of the immature follicle. Marked autophagic areas in the cytoplasm of the granulosa cells are indicated (arrows). D) An abundant quantity of vesicles containing residues of organelles from the death oocyte (arrowheads). Abundant elongated mitochondria are present in the well conserved cytoplasm of the granulosa cells (arrows). A lipid droplet (L) and the nucleus (NG) are shown. E) Granulosa cell included within a primary follicle with a complete nucleus (NG) in which heterochromatin and euchromatin can be observed. One lipid droplet (L) surrounded by polysaccharides and the presence of autophagy residual bodies (arrows) can be observed in the cytoplasm. Note the presence of the mitochondria and endoplasmic reticulum (arrowheads) in the proximity of the autophagy area (asterisk). F) The intercellular space between granulosa cells (thin arrows), and abundant mitochondria are shown. 


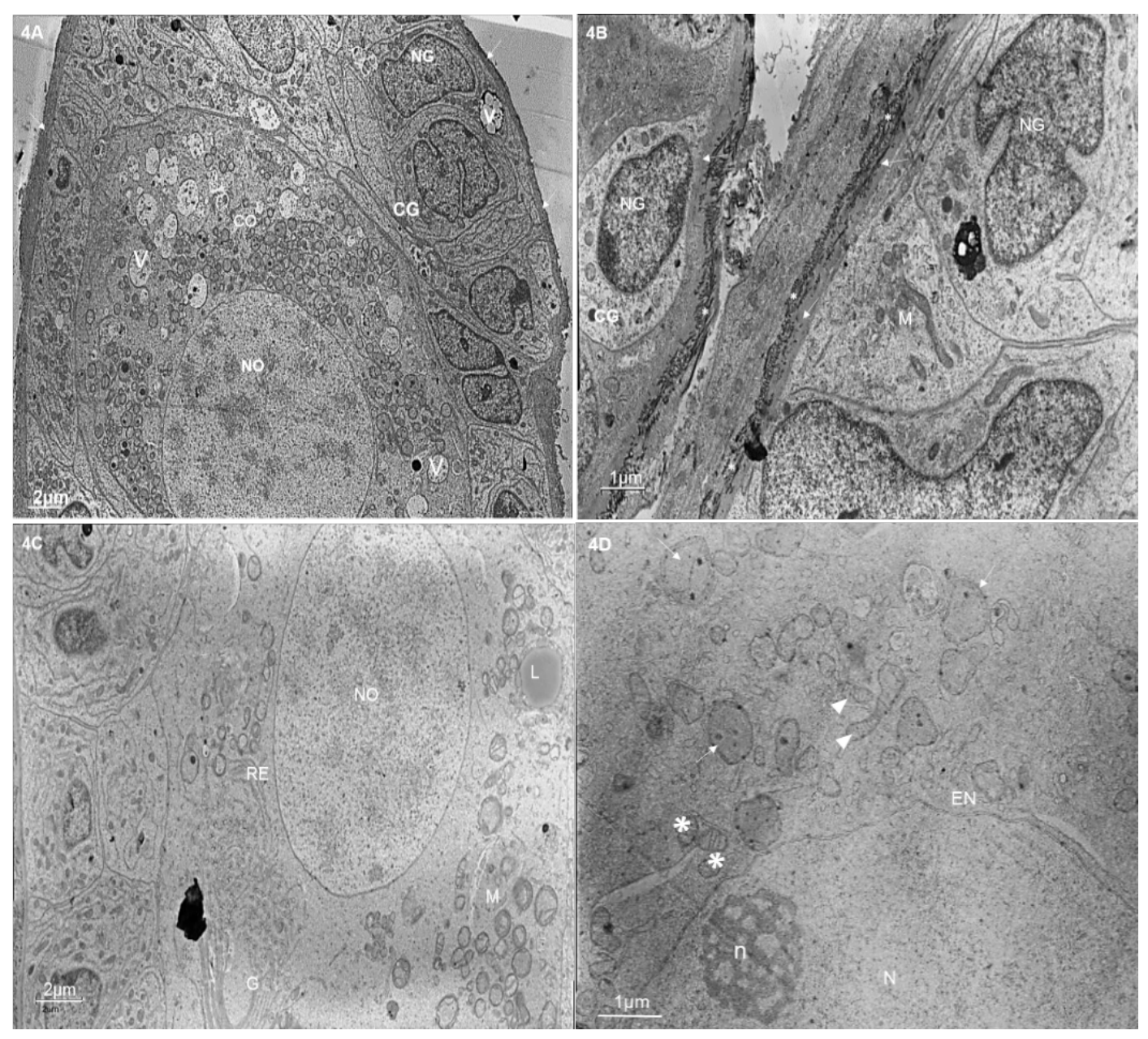

Figure 4. Ultrastructure of bovine immature follicles present in the ovarian cortex, treated with PBS immediately after ovary collection. Ovaries were washed and transported to the laboratory in phosphate buffered saline (PBS) to preserve per an established protocol. Images are presented as follows: A) An intact primary follicle with an intact basal membrane (arrows). Note the integrity of the granulosa cells and the oocyte. NO: oocyte nucleus; CO: oocyte cytoplasm; V: vesicles; NG: granulosa cell nucleus; CG: granulosa cell cytoplasm. B) Granulosa cells from different follicles, previously separated. Note the presence of mitochondria (M) with no alterations, as well as the tight union of the cell membranes of the granulosa cells. The basal membrane is complete, without damage as observed at this level of detection. M: mitochondria; NG: granulosa cell nucleus; CG: granulosa cell cytoplasm; basal membrane (arrows); collagen fibres (asterisks). C) An intact secondary follicle in which both unaltered granulosa cells and immature oocyte as observed at this level of detection. NO: oocyte nucleus; RE: endoplasmic reticulum; M: globular mitochondria; L: lipid droplet. D) Oocytes from primary and secondary follicles with well-defined cristae (asterisks), mitochondria in process of globular formation (arrowheads), and globular mitochondria (arrows). This morphology dynamic was observed in all of the immature oocytes; however, no signs of autolysis or immature oocyte degeneration are shown. N: nucleus; n: nucleolus; EN: nuclear envelope. 
of the mitochondria in the oocyte differed greatly from those of the granulosa cells. Most of the mitochondrial groups in the oocytes were globular, with the presence of lipid droplets; the cristae remained in some of the mitochondria while others were just spherical with their double membranes intact. Areas in which mitochondrial groups in different morphological stages or in the process of globular formation were also evident (Figures 4C and 4D), while the typical mitochondria with oval or rounded rod-like shape, as seen in the granulosa cells, were not present. Importantly, no signs of autolysis or degenerative processes, such as those found in the immature follicles treated with $\mathrm{OH}+\mathrm{NSS}$, were found.

Only the preantral follicles were evaluated because the objective of the study was to describe the quality of the follicles that are part of the quiescent pool in the ovarian cortex of female cattle. Proper functioning of the ovary is critical to maintain fertility and overall health, and ovarian function depends on the maintenance and normal development of ovarian follicles. The potential impact of oxidative stress induced for $70 \%$ ethanol during ovary collection on the immature follicles was evident, and the comparison of the percentage of morphologically normal follicles obtained in this study using OH + NSS and PBS (36.9\% vs $88.6 \%$ ) revealed this degenerative process. Rodrigues et al. ${ }^{17}$ reported a lower percentage of follicle normalcy with PBS treatment than that obtained in the present study (88.6 \% vs $77 \%$ ). Similar results were reported when the percentages obtained in this study were compared with those from other studies using ethanol for ovary asepsis, of $75 \%, 76 \%$ and $68.1 \%$, respectively. $9,15,16$

Alterations in morphology result from complex mechanisms that signal the start or degree of advancement of the atresia process at cellular level, and a wide variety of such alterations have been evaluated to demonstrate their correlation with the atresia signs at histological or ultrastructural level. ${ }^{23,24}$ Among histological variables, some that stand out are follicle crenation, the presence of vacuoles, organization of follicular cells around the immature oocyte, and nuclear integrity, all of which were found more frequently in this study. However, the number of morphological alterations increased in follicles treated with $\mathrm{OH}+\mathrm{NSS}$. Borges et al. ${ }^{10}$ reported this type of alterations in sow atretic immature follicles treated with an aseptic protocol similar to the OH+NSS treatment in the present study. Even though the atresia signs can accumulate during folliculogenesis, the existence of incomplete development of the metabolic functions, mainly in the immature oocyte mitochondria, has been reported. ${ }^{24}$ This prevents the oocyte from adequately dealing with the damage caused by the oxygen reactive species induced by ethanol at the ultrastructural level during asepsis. Additionally, damage becomes more evident with the acceleration of the atresia process. ${ }^{23}$

Evaluation at ultrastructural level confirmed the damage caused by ethanol included in the $\mathrm{OH}+\mathrm{NSS}$ treatment for ovary asepsis, mainly in both primary and secondary oocytes from immature follicles, in which only detritus and a great number of vesicles with organelles remains were observed. The combination of all these signs of degenerative changes indicates the occurrence of progressive atresia 23 at the immature oocyte level, unlike the immature follicles treated with PBS, which had no signs of atresia. One study showed that oocyte degeneration is the type of atresia more frequently observed in preantral follicles of this kind. ${ }^{25}$ Nonetheless, in the granulosa cells of most of the follicles treated with OH + NSS no signs of atresia were observed. This observation agrees with other studies ${ }^{10,25}$ reporting that in 
some preantral follicles, oocyte can degenerate or disappear completely, while the granulosa cells remain healthy and even continue to proliferate, indicating that the oocyte is more susceptible to degeneration than its own granulosa cells.

\section{Conclusions}

The present study demonstrates that $70 \%$ ethanol should not be used as an aseptic during ovary collection when the aim is to obtain and evaluate immature follicle stages. These results clearly show that the oocytes present in immature follicles undergo complete alteration. The use of buffer solutions, such as PBS, is recommended for aseptic collection and transport of ovaries to the laboratory. This will guarantee the integrity of immature follicles that can be used to conduct studies to evaluate the efficiency of the development and viability of immature follicles found in bovine ovarian cortical tissue with or without cryopreservation under laboratory conditions.

\section{Funding}

Jadiel Leonel Cisneros Prado is grateful for a thesis grant from Consejo Nacional de Ciencia y Tecnología (CONACYT).

\section{Acknowledgements}

The authors thank Juan Antonio López Orosco, Rosa María Cordero Pulido, Oscar Enrique Zarate Guevara, Alejandro Marmolejo Valencia and Adriana Castro Domínguez for providing technical assistance.

\section{Conflicts of interest}

The authors declare that they have no conflicts of interest.

\section{Author contributions}

Jadiel Leonel Cisneros Prado: conducted the experimental work, designed the research and wrote the manuscript.

Felipe Montiel Palacios: reviewed the manuscript and transcribed into English.

Rodolfo Canseco Sedano: performed results, reviewed the statistical analysis and drafting the manuscript.

Horacio Merchant Larios: conducted the research, interprets results and reviewed the manuscript.

\section{References}

1. Van den Hurk R, Zhao J. Formation of mammalian oocytes and their growth, differentiation and maturation within ovarian follicles. Theriogenology. 2005;63:1717-51. doi: 10.1016/j.theriogenology.2004.08.005.

2. Fair T. Follicular oocyte growth and acquisition of developmental competence. Anim Reprod Sci. 2002;78:203-16. doi: 10.1016/S0378-4320(03)00091-5. 
3. Asgari $F$, Valojerdi MR, Ebrahimi B, Fatehi B. Three dimensional in vitro culture of preantral follicles following slow-freezing and vitrification of mouse ovarian tissue. Cryobiology. 2015;71:529-36. doi: 10.1016/j.cryobiol.2015.11.001.

4. Silber $\mathrm{S}$, Kagawa N, Kuwayama M, Gosden R. Duration of fertility after fresh and frozen ovary transplantation. Fertil Steril. 2010;94(6):2191-6. doi:10.1016/j. fertnstert.2009.12.073.

5. Valente B, Alvares P, Hayashi J, Lopes B, Colombo MH, Gaitkoski D, Basso AC, Arnold DR, Marcondes M. A new direct transfer protocol for cryopreserved IVF embryos. Theriogenology. 2016;85:1147-51. doi: 10.1016/j. theriogenology.2015.11.029.

6. Santos RR, Amorim C, Cecconi S, Fassbender M, Imhof M, Lornage J, Paris M, Schoenfeldt $\mathrm{V}$, Martinez-Madrid B. Criopreservation of ovarian tissue: an emerging technology for female germline preservation of endangered species and breeds. Anim Reprod Sci. 2010;122:151-63. doi: 10.1016/j.anireprosci.2010.08.010.

7. Dittrich R, Lotz L, Keck G, Hoffmann I, Mueller A, Beckmann MW, Ven H, Montag M. Live birth after ovarian tissue autotransplantation following overnight transportation before cryopreservation. Fertil Steril 2012;97(2):387-90. doi: 10.1016/j.fertnstert.2011.11.047.

8. Rodriguez C, Rocha V, Penitente JM, De Azevedo JL, Gomes R, Alves CA. The base medium affects ultrastructure and survival of bovine preantral follicles cultured in vitro. Theriogenology. 2016;85:1019-29. doi: 10.1016/j. theriogenology.2015.11.007.

9. Carvalho AA, Faustino LR, Silva CMG, Castro SV, Lopes CAP, Santos RR, Báo $\mathrm{SN}$, Figueiredo JR, Rodrigues APR. Novel wide-capacity method for vitrification of caprine ovaries: Ovarian Tissue Cryosystem (OTC). Anim Reprod Sci. 2013;138:220-27. doi: 10.1016/j.anireprosci.2013.02.015.

10. Borges EN, Silva RC, Futino DO, Rocha-Junior CMC, Amorim CA, Báo SN, Lucci $\mathrm{CM}$. Cryopreservation of swine ovarian tissue: Effects of different of cryoprotectans on the structural preservation of preantral follicle oocytes. Cryobiology. 2009;59:195-200. doi: 10.1016/j.cryobiol.2009.07.003.

11. Albano E. Alcohol, oxidative stress and free radical damage. P Nutr Soc. 2006;65:278-90. doi: 10.1079/PNS2006496.

12. Hernández-Rodríguez S, Gutiérrez-Salinas J, García-Ortíz L, Mondragón-Terán P, Ramírez-García S, Núñez-Ramos NR. Estrés oxidativo y nitrosativo como mecanismo de daño al hepatocito producido por el metabolismo del etanol. Med Int Mex. 2014;(30):295-308.

13. Devine PJ, Perreault SD, Luderer U. Roles of reactive oxygen species and antioxidants in ovarian toxicity. Biol Reprod. 2012;86(2):27. doi: 10.1095/ biolreprod. 111.095224.

14. Amorim CA, Rodrigues APR, Rondina D, Gonçalves PBD, Figueiredo JR, Giorgetti A. Cryopreservation of ovine primordial follicles using dimethyl sulfoxide. Fertil Steril. 2003;79(1):682-86. doi: 10.1016/S0015-0282(02)04820-3.

15. Celestino J, Rodrigues R, Lopes C, Sousa F, Matos M, Melo M, Nair S, Ribeiro A, Viana J, Figueiredo J. Preservation of bovine preantral follicle viability and ultra-structure after cooling and freezing of ovarian tissue. Anim Reprod Sci. 2008;108:309-18. doi: 10.1016/j.anireprosci.2007.08.016.

16. Lopes CAP, Rodrigues APR, Celestino J, Melo M, Nogueira R, Cabral C, Viana J, Báo SN, Jewgenow K, Figueiredo J. Short-term preservation of canine pre- 
antral follicles: Effects of temperature, medium and time. Anim Reprod Sci. 2009;115:201-14. doi: 10.1016/j.anireprosci.2008.12.016.

17. Rodrigues APR, Amorim CA, Costa SHF, Matos MHT, Santos RR, Lucci CM, Báo SN, Ohashi OM, Figueiredo JR. Cryopreservation of caprine ovarian tissue using dimethylsulphoxide and propanediol. Anim Reprod Sci. 2004;84:211-27. doi: 10.1016/j.anireprosci.2003.12.003.

18. Cavalcante AYP, Gouveia BB, Barberino RS, Lins TLBG, Santos LP, Gonçalves RJS, Celestino JJH, Matos MHT. Short Communication: kit ligand promotes the transition from primordial to primary follicles after in vitro culture of ovine ovarian tissue. Zygote. 2015;1-5. doi: 10.1017/S0967199415000556.

19. Santos RR, Tharasanit T, Figueiredo JR, Van Haeften T, Van den Hurk T. Preservation of caprine preantral follicle viability after cryopreservation in sucrose and ethylene glycol. Cell Tissue Res. 2006;325:523-531. doi: 10.1007/ s00441-006-0193-5.

20. Fransolet M, Labied S, Henly L, Masereel MC, Rozet E, Kirschvink N, Nisolle M, Munaut C. Strategies for using the sheep ovarian cortex as a model in reproductive medicine, PLoS One. 2014;9(3):e91073. doi: 10.1371/journal. pone.0091073.

21. Hayashi M, Hariya M, Kayano M, Suzuki H. Brief communication. Distribution of follicles in canine ovary - A simple and rapid method for counting follicles. Cryobiology. 2015;71:514-51. doi: 10.1016/j.cryobiol.2015.08.014.

22. Merchant-Larios H, Moreno-Mendoza N, Buehr M. The role of the mesonephros in cell differentiation and morphogenesis of the mouse fetal testis. Int J Dev Biol. 1993;37:407-15.

23. De Bruin JP, Dorland M, Spek ER, Posthuman G, Van Haaften M, Looman CWN, Te Velde ER. Ultrastructure of the resting ovarian follicle pool in healthy young women. Biol Reprod. 2002;66:1 151-60. doi: 10.1095/biolreprod66.4.1151.

24. Paulini $F$, Carvalho R, Jivago JL, Lucci CM. Ultrastructural changes in oocytes during folliculogenesis in domestic mammals. J Ovarian Res. 2014;7:102. doi: 10.1186/s13048-014-0102-6.

25. Lucci CM, Rumpf R, Figuereido JR, Báo SN. Zebu (Bos indicus) ovarian preantral follicles: morphological characterization and development of an efficient isolation method. Theriogenology. 2002;57:1467-83. doi: 10.1016/ S0093-691X(02)00641-6. 